\title{
BONE REGENERATION CAPACITY OF ADIPOSE TISSUE-DERIVED STEM CELLS IN RABBIT PERIODONTITIS-INDUCED BONE DEFECT MODEL
}

\author{
Gulzhan Yermukhanova', Vladimir Rusanov², Aliya Bayakhmetova³ , Yuliya Menchisheva² ID , Gulzakira Ksetaeva', \\ Nurzhamal Yermukhanova'
}

'Department of Pediatric Dentistry, S.D. Asfendiyarov Kazakh National Medical University, Almaty, Kazakhstan 2Department of Surgical Dentistry, S.D. Asfendiyarov Kazakh National Medical University, Almaty, Kazakhstan ${ }^{3}$ Department of Therapeutic Dentistry, S.D. Asfendiyarov Kazakh National Medical University, Almaty, Kazakhstan

\begin{abstract}
INTRODUCTION: Periodontitis is one of the most common oral infectious disease. Adipose tissue-derived mesenchymal stem cells (AD-MSCs) have become widely studied for their possibilities for regeneration of periodontal bone defect. However, bone regeneration efficiency of AD-MSCs combined with transplantation materials in periodontal bone defects remains unclear.

ОвJестіves: The purpose of the study was to compare the effects of two repair methods with and without application of AD-MSCs in a rabbit's periodontal defect model.

MATERIAL AND MEthods: Experimental periodontitis was initiated in eighteen rabbits. Animals were divided into two groups, including Col-HA only (group 1) and Col-HA + AD-MSCs (group 2), and implanted in rabbit periodontitis-induced bone defect. To evaluate difference in these two groups, we used histological analysis of the samples and X-ray. For comparison of grey-level frequency in X-ray samples of the two groups, Otsu's method was applied.

RESULTS: Post-operative wounds in group 2 healed three days earlier than in group 1, starting from a formation of fibrous tissue, cartilage, and osteoid tissue, and ending with a formation of full-plate bone tissue. X-ray evaluations showed that more intensive reparative regeneration in post-operative bone cavity was observed in animals of group 2. The $90^{\text {th }}$ day samples with AD-MSCs presented more differentiated gray-level than the $90^{\text {th }}$ day samples without AD-MSCs.

ConcLusions: The results of the study suggest that the use of transplantation material (Col-HA) with AD-MSCs has positive effects, contributing to the improvement of reparative regeneration of bone tissue in the periodontal bone defect area.
\end{abstract}

KEY WORDS: experimental periodontitis, bone regeneration, adipose tissue-derived mesenchymal stem cells, periodontal surgery.

J Stoma 2021; 74, 4: 227-235

DOI: https://doi.org/10.5114/jos.2021.111655

\section{JOURNAL OF} STOMATOLOGY CZASOPISMO STOMATOLOGICZNE

AdDress For CORRESPONDENCE: Yuliya Menchisheva, Department of Surgical Dentistry, S.D. Asfendiyarov Kazakh National Medical University, Almaty, Kazakhstan, e-mail: menchisheva.y@kaznmu.kz 


\section{INTRODUCTION}

Periodontitis is one of the most common oral in fectious disease, which affects the periodontium $[1,2]$. The most important targets in the treatment of periodontitis are relief of inflammation and provision of optimal processes of bone tissue reparative regeneration of the alveolar process of the jaw [3, 4]. Considering that restoration of periodontal tissues involves replacement of lost structures, including the bone of the alveolar bone, the attention of most researchers aims at replacing lost bone tissue with various transplantation and implantation materials. However, numerous studies have shown that the use of biological materials can only improve clinical condition of periodontal tissues [5]. Current bone grafting materials present only osteogenic and osteoinductive abilities. That is why the use of stem cells, along with various transplantation materials, seems attractive for the repair and healing of bone defects.

The purpose of periodontal regeneration is to restore the damaged bone, root cementum, and periodontal ligament. The use of stem cells has been shown a promising approach in periodontal research and tissue engineering [6]. Stem cells have become widely studied over the past years for their clinical potential, and enormous therapeutic possibilities. The term 'stem cell' defines a population of low-differentiated cells, with the ability to self-renew by division and differentiation into cellular components of various tissues [7].

Cells that provide direct bone tissue repair are a culture of osteogenic cells, which can be obtained by directed differentiation of mesenchymal stem cells (MSCs) of bone marrow, adipose tissue, or other sources, such as periosteum, spleen, thymus, placenta, etc. [8]. Different studies have demonstrated that MSCs show potential in regenerative medicine. Among different MSCs, bone marrow MSCs (BMMSCs), adipose-derived MSCs (AD-MSCs), and dental stem cells (DSCs) have received much attention for bone and dental tissue regeneration [9-12]. DSCs and BMMSCs have been shown their efficiency for periodontal regeneration in animal studies [13-16]. Moreover, several studies have shown promising results of the use of DSCs and BMMSCs on humans [17-19].

One of the promising sources of MSC is the adipose tissue. Studies on immuno-phenotype of adipose tissuederived mesenchymal stem cells (AD-MSCs) demonstrated that they are almost identical to MSC obtained from bone marrow. Using of AD-MSCs have significant advantages, including comparative accessibility, simplicity, and safety of their products in comparison with methods for stem cell collection from other sources [20]. A harvesting method is less invasive, and AD-MSCs could be obtained in high number from liposuction or subcutaneous adipose tissue fragments [6].

Although composite transplantation materials are widely used in bone tissue defect repair, bone tissue-en- gineering had been described in many studies as a new promising method for bone defects reconstruction, including periodontitis-induced bone defects. AD-MSCs have good proliferation properties and osteogenic capabilities. There are several studies showing the efficacy of AD-MSCs in repairing bone defects [21-24]. Therefore, further studies should be done to investigate potential, and prove safety and effectiveness of AD-MSCs for the improvement of reparative regeneration of bone tissue in the area of periodontal bone defect. In order to reveal whether the use of composite transplantation materials (collagen with hydroxyapatite, Col-HA) in combination with $\mathrm{AD}-\mathrm{MSCs}$ (active transplantation material) could be a real alternative to using Col-HA only (passive transplantation material), AD-MSCs differentiation capacity and established procedures for isolation and culture of rabbit AD-MSCs were assessed in the present study.

\section{OBJECTIVES}

The purpose of the study was to compare the effects of two repair methods with and without application of AD-MSCs in a rabbit's periodontal defect model.

\section{MATERIAL AND METHODS}

Statistical methods were used to predetermine sample size, with a minimum of nine animals per group in order to detect a difference at $95 \%$ confidence $(p=0.05)$. In total, 18 Chinchilla rabbits (males; 3.5 to $4.5 \mathrm{~kg}$ each) were used in the experiment. The animals were cared for at the animal laboratory of S.D. Asfendiyarov Kazakh National Medical University. Adult males housed at a temperature of $21 \pm 1^{\circ} \mathrm{C}$ and humidity-controlled $50 \% \pm 10$ rooms. The plastic cages were $60 \mathrm{~cm}$ in length, $40 \mathrm{~cm}$ in width, and $20 \mathrm{~cm}$ in height. Cage bedding consisted of heat-treated shavings spread at a depth of $4 \mathrm{~cm}$. The animals received water and were fed for at least 7 days before the experiment for acclimatization.

All the rabbits were identified by earmarks and numbered accordingly. Using a table of random numbers, the animals were divided into 2 groups: group 1 (Col-HA only, $n=9$ ), with post-operative bone cavity filled with composite transplantation material based on bone collagen and hydroxyapatite in equal weight proportions, and group 2 (Col-HA+ AD-MSCs, $n=9$ ), where post-operative bone cavity was filled with a material on the base of bone collagen, hydroxyapatite, and adipose tissuederived mesenchymal stem cells. Animals from the group 2 were always treated first, followed by the group 1 . During analyses of experiments, the researchers were blinded.

To induce experimental periodontitis, ligature placement (tantalum wire) around the incisors tooth was performed under general anesthesia, using $40 \mathrm{mg}$ ketamine/ 
TABLE 1. Mean concentration of stromal cells after receiving primary cell suspension

\begin{tabular}{|l|c|}
\hline Sample name & $\begin{array}{c}\text { Number of stromal cells of adipose tissue } \\
\left(1,000 \text { cells in } \mathbf{c m}^{3}\right) \text {, mean } \pm \text { SD }\end{array}$ \\
\hline Adipose tissue, No.1 & $10,645 \pm 564$ \\
\hline Adipose tissue, No. 2 & $11,755 \pm 765$ \\
\hline Adipose tissue, No. 3 & $10,467 \pm 385$ \\
\hline Adipose tissue, No. 4 & $12,687 \pm 841$ \\
\hline Adipose tissue, №. 5 & $11,212 \pm 645$ \\
\hline Adipose tissue, No. 6 & $10,765 \pm 588$ \\
\hline Adipose tissue, No.7 & $10,891 \pm 631$ \\
\hline Adipose tissue, No. 8 & $11,455 \pm 565$ \\
\hline Adipose tissue, No.9 & $11,436 \pm 448$ \\
\hline
\end{tabular}

$\mathrm{kg}$ of body weight and $5 \mathrm{mg} / \mathrm{kg}$ xylazine injections. Two weeks later, a typical picture of local periodontitis developed (Figure 1).

Autologous AD-MSCs were isolated and expanded two weeks before surgery from all the rabbits of group 2 . In experimental animals, immediately after the application of wire ligatures, adipose tissue was taken from the omentum, located on the front surface of transverse colon of the rabbit's abdominal cavity. Suturing of the peritoneum and skin were performed independently. Adipose tissue was placed in a Hanks' solution and sent to laboratory of Scientific-Production Enterprise Antigen (Almaty, Kazakhstan) to isolate AD-MSCs with a concentration of 1 million cells in $1 \mathrm{~cm}^{3}$. Enzymatic digestion was performed using collagenase-1 (Sigma) at a concentration of $0.075 \%$ at $37^{\circ} \mathrm{C}$, with continuous shaking for $45 \mathrm{~min}$. Enzymatic dissociation was stopped by the addition of phosphate buffer saline (PBS) and a 10\% fetal bovine serum. Cell clumps were separated with a centrifuge at 1,200 for 10 minutes at $4^{\circ} \mathrm{C}$. Cells were resuspended in MesenCult. Then, cells were seeded onto a tissue culture polystyrene dish and kept at $37^{\circ} \mathrm{C}$ under $5 \% \mathrm{CO}_{2}$. After receiving the primary cell suspension, the concentration and the total number of cells from the sample were calculated. The results are presented in Table 1.

MesenCult was replenished at $24 \mathrm{~h}$ intervals, and cell monolayer was formed on the $6 / 7^{\text {th }}$ day of cultivation and was represented mainly by fibroblast-like cells. Morphometric system of Leica company (DM 1000 microscope and a DFC-320 digital camera, Germany) was used for photographing the results (Figure 2).

In the process of passage using MesenCult nutrient medium, an increase was observed at the first passages. The results of counting the concentration of cells are shown in Table 2.

Plastic-adherent cells were analyzed with a positive marker of CD +90 after $3^{\text {rd }}$ passage. Additionally, cells were identified as mesenchymal stem cells by their morphology using scanning electron microscopy.
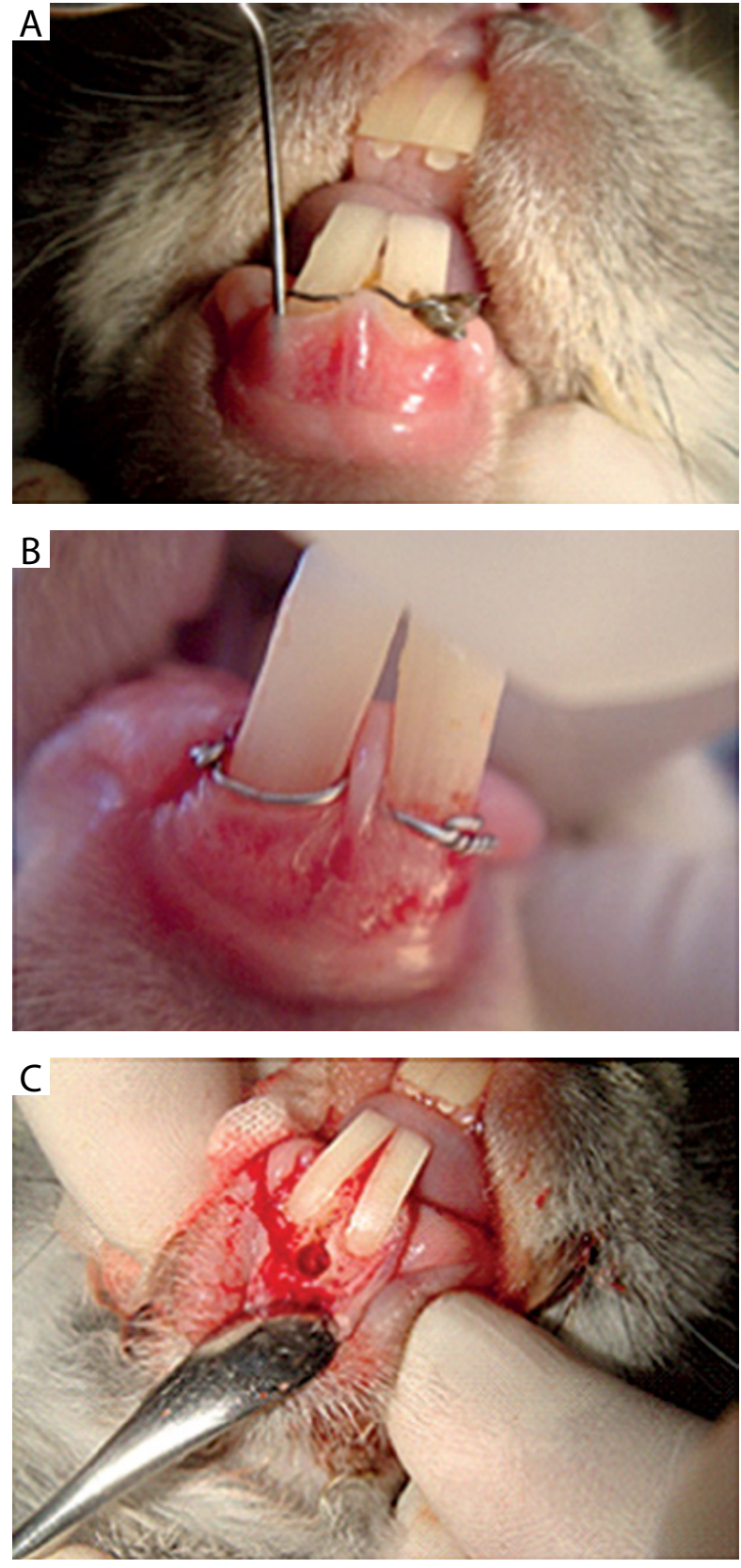

FIGURE 1. Picture of a developed local periodontitis in a rabbit and formed bone defect on the vestibular surface of the alveolar process

$\mathrm{AD}-\mathrm{MSCs}$ in $5^{\text {th }}$ passage were selected for all in vivo experiments. Approximately 1 million cells in $\mathrm{cm}^{3}$ were used per transplantation. Two experimental modalities were allocated to 18 periodontal bone defects, as follows: 50\% Col-50\% HA (HA, 10 mg, UCOC, Shymkent, and incorporated into collagen-1 fibrils); $50 \%$ Col-50\% HA seeded with $1 \times 10^{6} \mathrm{AD}$-MSCs and immediately implanted into the bone defects. Biocompatibility of Col-HA was evaluated using cytotoxicity assays with AD-MSCs in vitro.

In the area of developed local periodontitis, osteogingivoplasty was performed. After careful curettage of periodontal pockets, vertical flaps were cut from both 

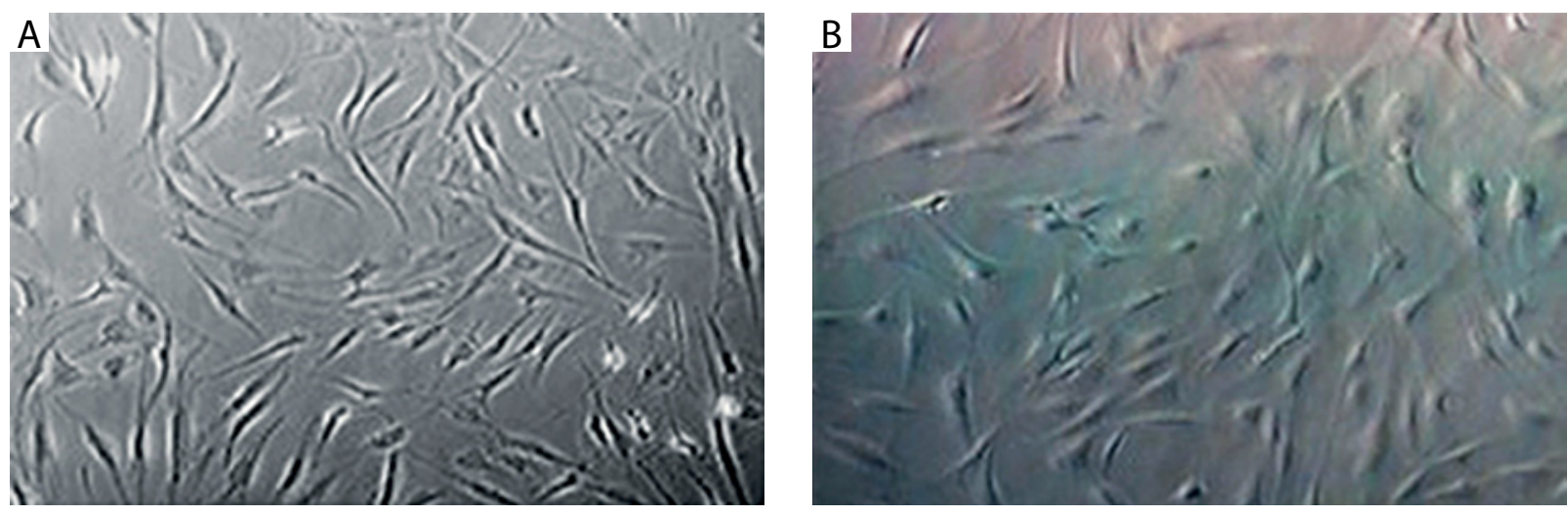

FIGURE 2. AD-MSCs in third passage (A) and fifth passage (B). Magnification $\times 400$

TABLE 2. Mean concentration of AD-MSCs after fifth passage

\begin{tabular}{|l|c|}
\hline $\begin{array}{l}\text { Name of adipose tissue stromal } \\
\text { cell sample }\end{array}$ & \multicolumn{1}{|c|}{$\begin{array}{c}\text { Number of cells after fifth } \\
\text { passage (million cells in } \mathrm{cm}^{3} \text { ) }\end{array}$} \\
\hline AD-MSCs, No. 1 & $1,018,000$ \\
\hline AD-MSCs, No. 2 & $1,015,000$ \\
\hline AD-MSCs, No. 3 & 860,000 \\
\hline AD-MSCs, No. 4 & 910,000 \\
\hline AD-MSCs, No.5 & 985,000 \\
\hline AD-MSCs, No.6 & 920,000 \\
\hline AD-MSCs, No.7 & 915,000 \\
\hline AD-MSCs, No.8 & $1,020,000$ \\
\hline AD-MSCs, No. & $1,005,000$ \\
\hline
\end{tabular}

surfaces of the alveolar ridge to the maximum depth of periodontal pockets. A through bone defect was formed in the inter-root septum of the central incisors of the lower jaw, with a diameter of $2 \mathrm{~mm}$. In the group 1 animals, post-operative bone cavity was filled with Col-HA. In the group 2, bone defect was replaced with Col-HA and AD-MSCs.

The animals were sacrificed using anesthesia at 15 , 30 , and $90^{\text {th }}$ days following osteo-gingivoplasty, respectively. The sawed bone blocks from the operation area were fixed in a $10 \%$ formalin before processing and embedding in paraffin wax. X-ray examination of bone blocks was performed on a digital X-ray apparatus (Ti$\tan 2000-V)$ at 15,30 , and $90^{\text {th }}$ days accordingly. To evaluate difference of X-ray results of the two groups (for both bone collagen and hydroxyapatite, and bone collagen and hydroxyapatite with AD-MSCs), we used a comparison of pixel frequency of gray-level of the $90^{\text {th }}$ day. For a comparison of frequency of grey-level in X-ray samples of the two groups, we used Otsu's method (Otsu, 1979) [25]. Histograms were managed using ImageJ program.

Percentage of newly formed $\left(\mathrm{V}_{\mathrm{b}}\right)$ bone was calculated as a rate between the volume $\left(\mathrm{mm}^{3}\right)$ of newly formed bone $\left(\mathrm{V}_{\mathrm{n}}\right)$ and the volume of original bone $\operatorname{defect}\left(\mathrm{V}_{\mathrm{o}}\right)$.
Bone sections were deparaffinized and fixed. The sections (10-12 $\mu \mathrm{m}$ thick) were stained with hematoxylin and eosin, Van Gieson's, and observed using a microscope. During histological analysis of the samples, we focused on the comparison between newly formed bone and tissue ossification with and without matching AD-MSCs in the two groups of samples.

Differences in X-ray measurements between the groups at each time point were compared using Mann-Whitney $U$-test, with $p<0.05$ considered statistically significant. SPSS software package (version 12.0; SPSS, Chicago, IL, USA) was applied for statistical analyses.

The study was registered on a registration site (https:// science.kaznmu.kz/ntp-mon-rk; registration No. 177). All experimental procedures in the present study were performed according to recommendations of the National Institutes of Health Guide for Care and Use of Laboratory Animals, complied with the ARRIVE guidelines, and were approved by local ethics' commission at S.D. Asfendiyarov Kazakh National Medical University, Almaty, Kazakhstan (protocol No. 10415-30).

\section{RESULTS}

Clinical observations of the post-operative period in both groups of animals showed that after surgical procedure, moderate soft tissue swelling was determined, which gradually increased and reached its' maximum size on third day. Then, post-operative soft tissue edema gradually decreased and completely disappeared in the group 1 in 9 days and in the group 2 in 6 days $(p<0.05)$. In the group 1, the epithelialization of post-operative wounds occurred on day 11 . On the other side of the analysis was the group 2 wound epithelialization, which ended on $8^{\text {th }}$ day after surgical procedure $(p<0.05)$. Adverse events or side effects after using bone collagen, hydroxyapatite, and AD-MSCs were not observed.

$\mathrm{X}$-ray examinations conducted at various times after surgical procedure allowed for dynamic tracing of the regenerative processes in the area of the defect of experimentally reproduced periodontitis. 

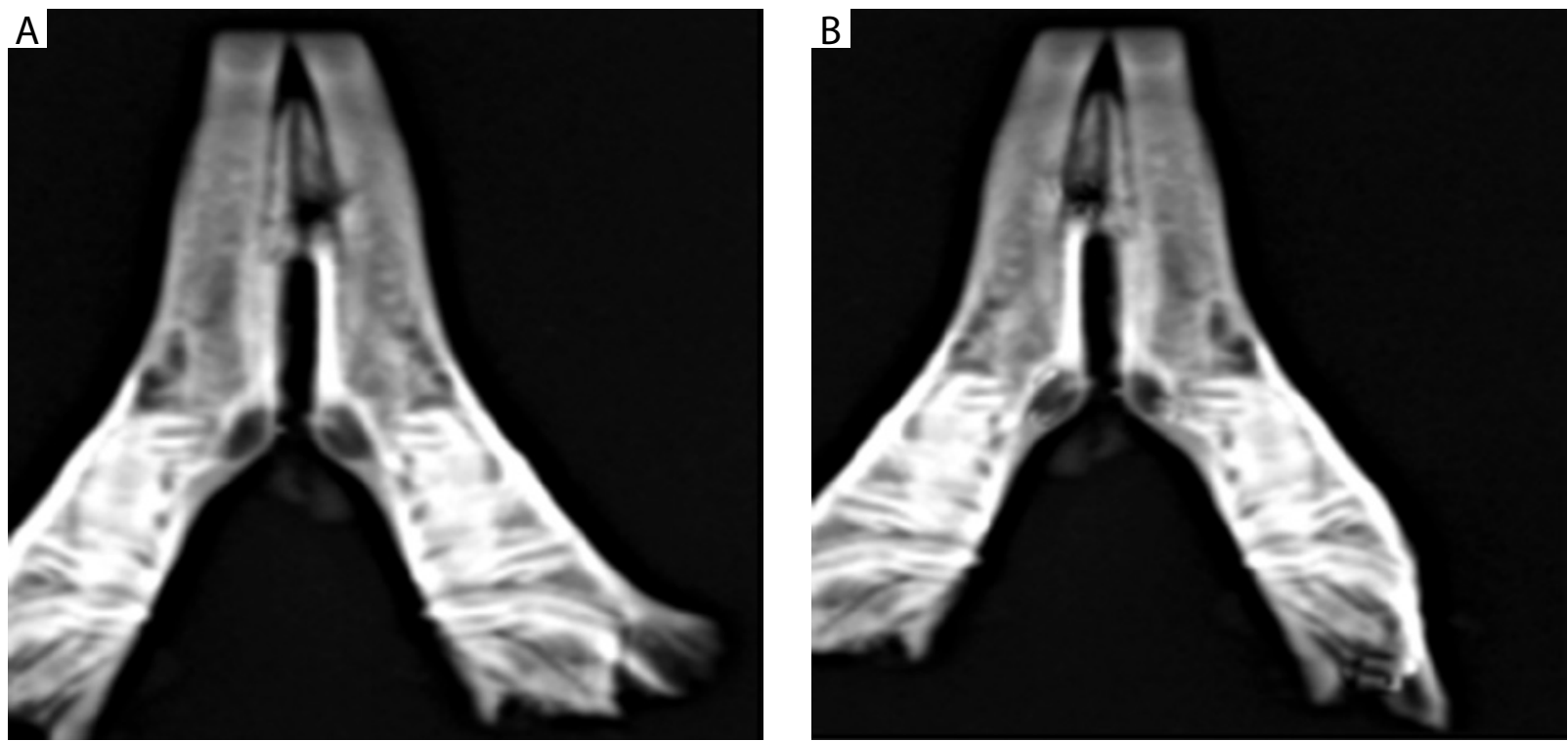

FIGURE 3. X-ray of a fragment of the lower jaw of a rabbit on $15^{\text {th }}$ day after surgery in the group 1 (A) and in the group 2 (B)
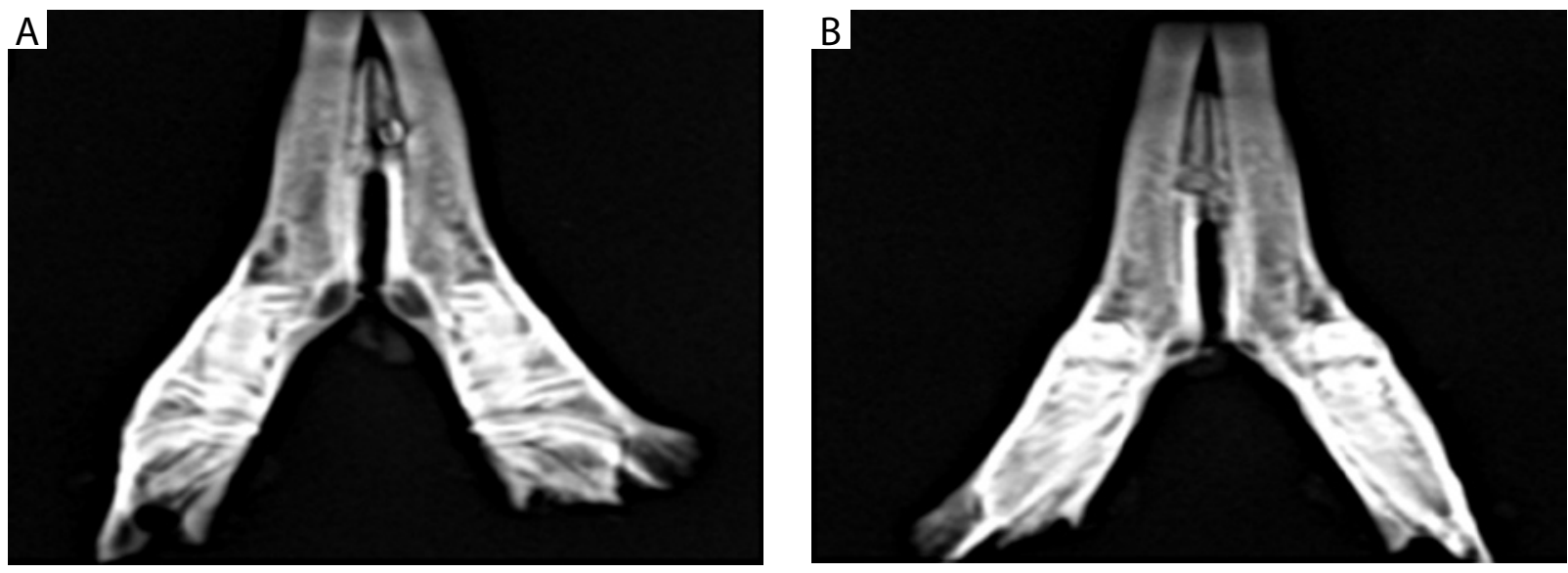

FIGURE 4. X-ray of a fragment of the lower jaw of a rabbit on $30^{\text {th }}$ day after surgery in the group 1 (A) and in the group 2 (B)

On the $15^{\text {th }}$ day after the operation, a comparatively clear contour of a bone defect with a diameter of $2 \mathrm{~mm}$ was determined in the group 1 . In the group 2, the contour of the defect was unclear and had a form of narrow strip. In a bone defect, well-defined shadows of irregular shape of newly formed regenerate were determined (Figure 3).

On the $15^{\text {th }}$ day after the procedure, the mean value of $\mathrm{V}_{\mathrm{b}}$ in the group 1 was $32.6 \pm 0.3$. The mean value of $\mathrm{V}_{\mathrm{b}}$ in the group 2 was $45.8 \pm 0.2$, approximately 1.4 times more than in the experimental group $(p=0.05)$.

On the $30^{\text {th }}$ day after the operation, the bone defect was reduced in size in animals of both the groups. Central part of bone defects had low density, but in the group 2 animals, the bone loss was less pronounced (Figure 4).

On the $90^{\text {th }}$ day after the surgery, the bone defect was reduced in size due to newly formed bone tissue in the animals of group 1, but in the central part of bone defect, the shadow of regenerate presented with low density. It was not possible to determine the bone defect by 90 days in the animals of group 2. Mature bone tissue was determined at the place of a pre-existing defect (Figure 5).

On the $90^{\text {th }}$ day after the operation, the mean value of $\mathrm{V}_{\mathrm{b}}$ in the group 1 was $82.3 \pm 0.3$. The mean value of $\mathrm{V}_{\mathrm{b}}$ in the group 2 was $97.2 \pm 0.2$, approximately 1.2 times more than in the experimental group $(p=0.05)$, which could be interpreted as the newly formed bone, which almost filled the defect, with nearly no black areas.

On the $90^{\text {th }}$ day after the operation, the mean value of gray-level in the group 1 was $130.7 \pm 1.6$, whereas in the group 2, it was $141.0 \pm 1.3(p=0.05)$. The $90^{\text {th }}$ day samples with AD-MSCs presented a more differentiated gray-level than the $90^{\text {th }}$ day samples without AD-MSCs (Figure 6).

According to the histology of the group 1, post-operative defect was filled with granulation tissue, which 

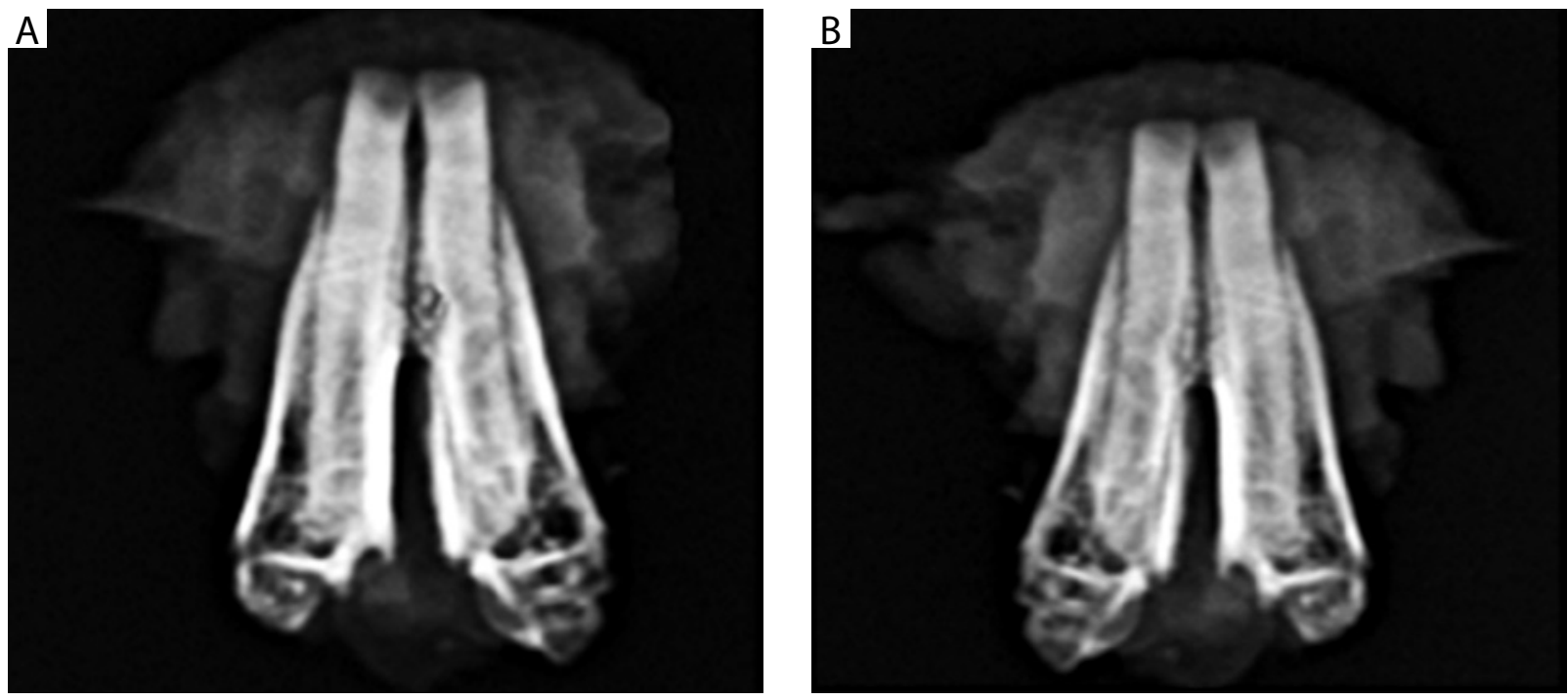

FIGURE 5. X-ray of a fragment of the lower jaw of a rabbit on $90^{\text {th }}$ day after surgery in the group 1 (A) and in the group 2 (B)
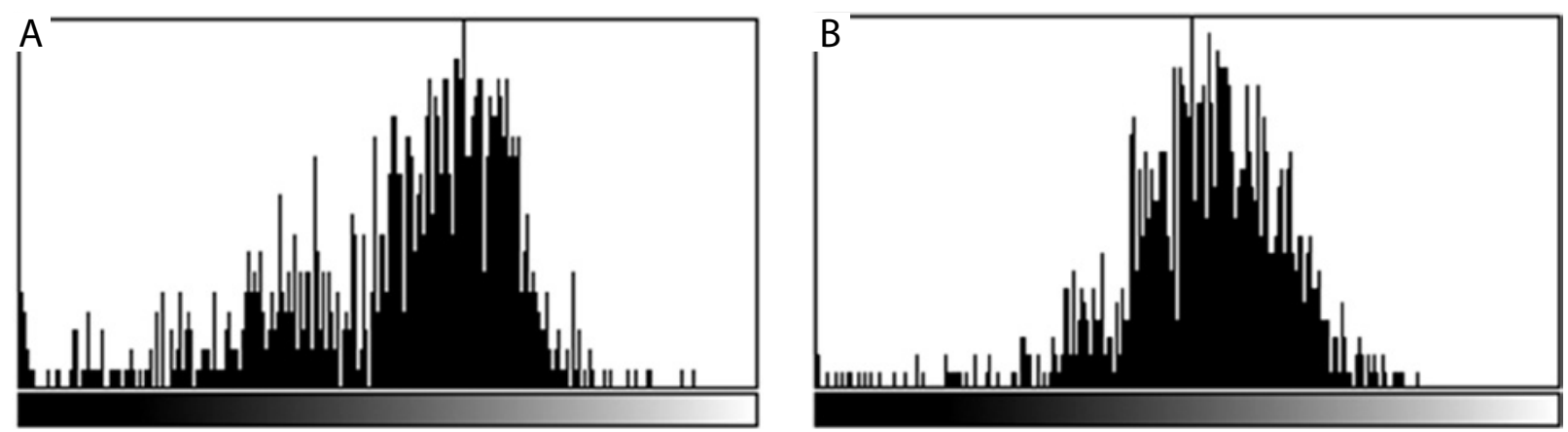

FIGURE 6. Pixel frequency of gray-level in the samples of the group 1 (A) and the group 2 (B)

contained numerous blood vessels and fibrous structures of young connective tissue with differentiating cellular elements, on the $15^{\text {th }}$ day after the procedure. Around the bone defect, a decomposition of osteons with a loss of the usual tinctorial properties was noted. Osteocytes showed signs of dystrophy with karyolysis and karyopicnosis. Thin collagen fibers, weakly stained using Van Gieson method, appeared among the cells. On the periphery of a granulation tissue, weakly expressed chondroid structures were determined. In the group 2 samples, the central part of the bone defect was filled with mature cell-fibrous connective tissue, which was rich in small vessels and cell elements (mostly macrophages, lymphocytes, and fibroblasts), stained using Van Gieson technique in bright red color. Separate micro-fragments of biocomposite were found in marginal regions of the defect. On the periphery of these foci, foci of maturation of granulations appeared with a formation of mature connective tissue growing from peripheral areas on the side of the bone tissue surrounding the bone defect (Figure 7).

On the $30^{\text {th }}$ day, large foci of growth of fibrous tissue in the central part of the bone defect were detected in the samples of group 1. Among the cellular fibrous tissue, chondroid structures had appeared in peripheral parts of the bone defect. Resorptive processes with participation of osteoclasts from the maternal bone side become less pronounced. In the group 2, the post-operative bone defect was almost completely replaced by newly formed bone tissue, although the processes of further structural reorganization were underway in the bone tissue. In the peripheral part of the bone defect, the regenerate had become more powerful and formed compact osteon systems. In the center of the defect, thin bone plates with numerous adhesion lines appeared. Bone plates were oriented in the same direction as vascular canals (Figure 8).

On the $90^{\text {th }}$ day, the bone defect was filled with a coarse bone tissue in the peripheral part of the defect in the group 1. Bone regenerate layers were represented by thick trabeculae. In central sections of the bone defect, sections of osteoid tissue were still determined, without mineralization processes. Osteon systems were poorly developed, and bone trabeculae were located randomly. Bone regenerate filling the post-operative defect continued to undergo further reconstruction. Partial compaction of a newly 

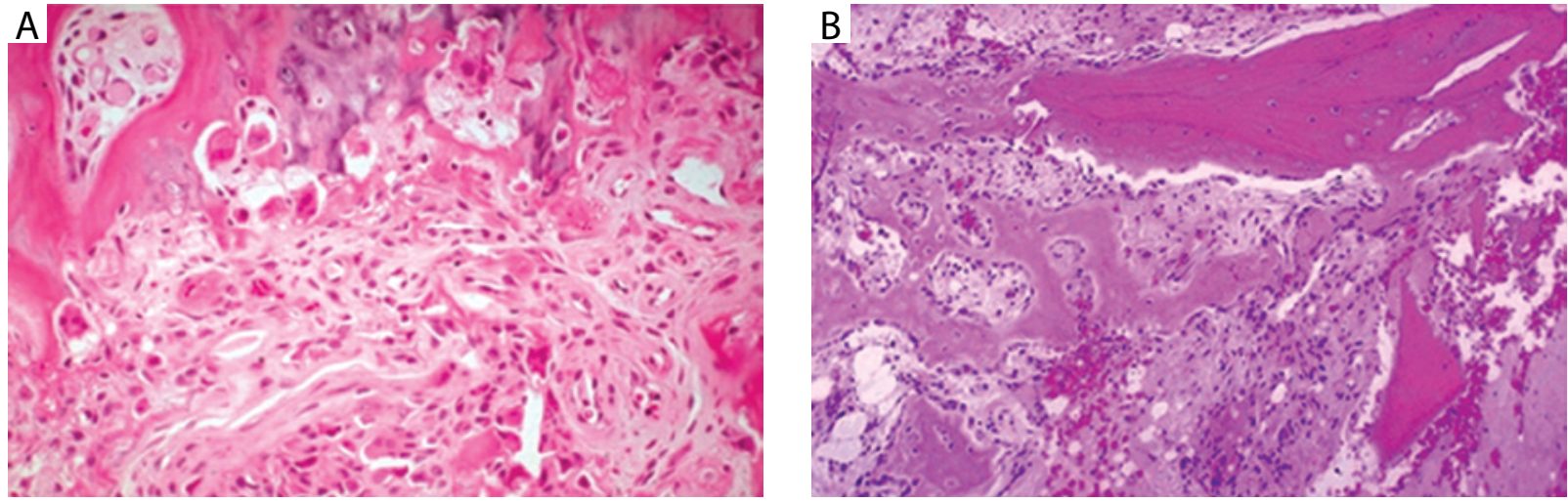

FIGURE 7. 15 days interval. A) Photomicrograph of the group 1 ( $H \& E, \times 100)$. B) Photomicrograph of the group 2 $(H \& E, \times 100)$
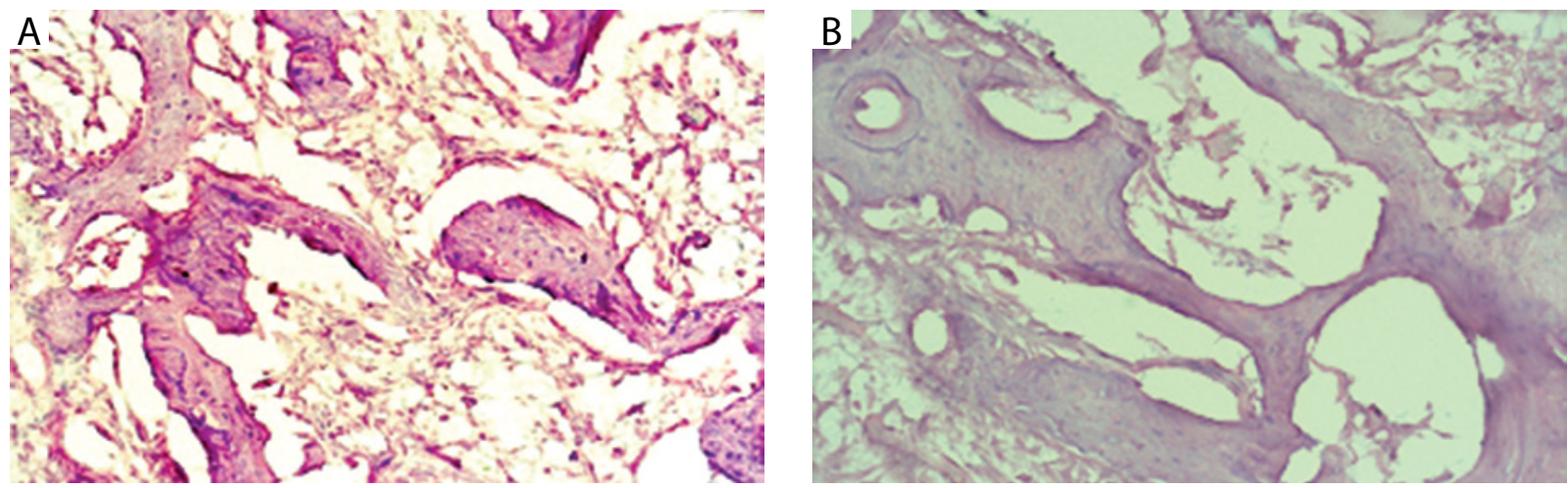

FIGURE 8. 30 days interval. A) Photomicrograph of the group $1(H \& E, \times 100)$. B) Photomicrograph of the group 2 $(H \& E, \times 100)$
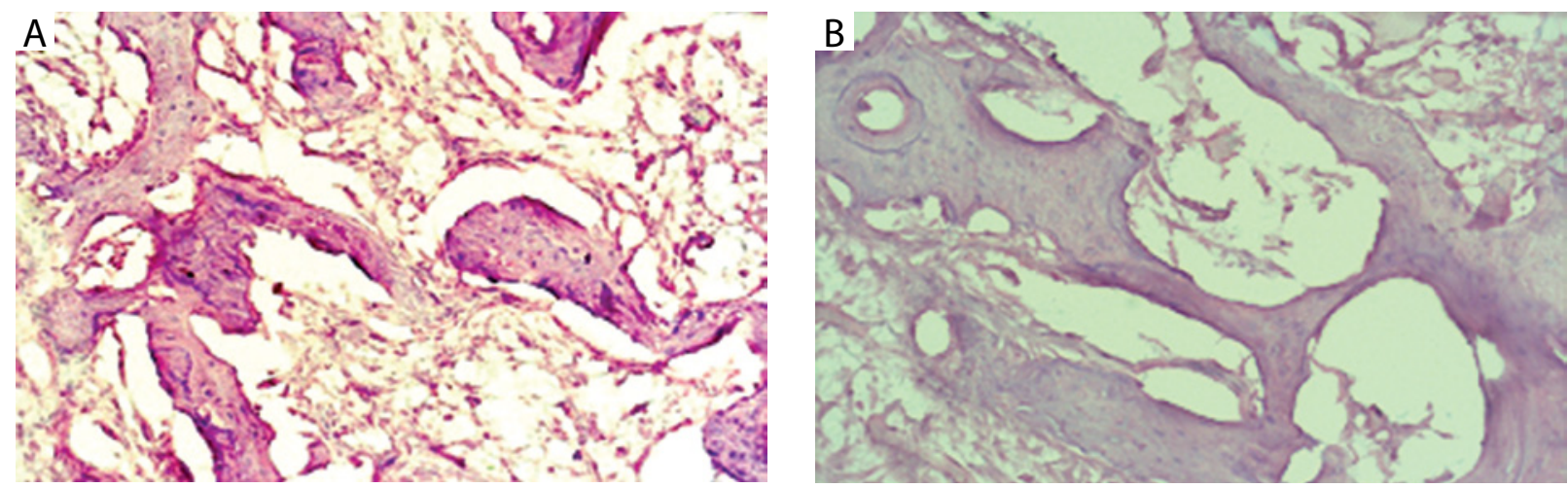

FIGURE 9. 90 days interval. A) Photomicrograph of the group 1 ( $H \& E, \times 100)$. B) Photomicrograph of the group 2 $(H \& E, \times 100)$

formed bone substance was observed, and bone matrix acquired a coarse fiber appearance. In the peripheral part of the regenerate, the bone matrix acquired a lamellar structure. In the samples of group 2, it becomes impossible to histologically determine a place of a bone defect in alveolar process of the lower jaw, since the structure of bone regenerate and the maternal bone form one whole (Figure 9).

\section{DISCUSSION}

Periodontitis is a heterogeneous disease in etiology that affects millions of people [26]. Periodontitisinduced bone defects remains a practical health problem and pose challenges for bone reconstruction. The hypothesis of our study was that the use of composite transplantation material based on collagen and hydroxyapa- 
tite (Col-HA) with AD-MSCs promote an early repair of periodontal bone defect. The results presented in the current study indicated that transplantation materials combined with AD-MSCs have better ability to promote bone regeneration and osseointegration; the bone volume density in the Col-HA + AD-MSCs group was significantly greater than that in the Col-HA only group.

According to the literature, scaffold materials can influence cellular response and support bone formation [27]. Different transplantation materials have been described and used in bone tissue engineering, such as collagen, hydroxyapatite, demineralized bone matrix, xenografts, and synthetic bone grafts. All these materials showed osteo-conduction capacity for bone regeneration [28]. Osteo-conduction is the process that permits bone apposition from existing bone [29]. Collagen and hydroxyapatite that were used in the current study are osteo-conductive materials. However, when combined with AD-MSCs, they could promote transformation of mesenchymal cells into osteoblasts [30]. Stem cells combined with the use of biomaterials, is becoming popular in periodontal regeneration. Stem cell-based therapy represents a new approach for bone repair and regeneration, especially in case of periodontitis-induced bone defects [31].

Undoubtedly, more human researches are required to prove positive aspects of the use of AD-MSCs in dental practice. Many studies show promising results on animal models in terms of regeneration of bone $[32,33]$.

In the present study, we demonstrated that the use of transplantation material on the base of bone collagen, hydroxyapatite, and adipose tissue-derived mesenchymal stem cells after osteo-gingivoplasty, leads to an earlier mineralization and bone formation, when compared with a bone collagen-based transplantation material, i.e. hydroxyapatite, which may help to ensure the reconstruction of alveolar bone defect. A significant number of in vivo and in vitro studies have been conducted to evaluate the regenerative capacity of AD-MSCs. Most studies investigated AD-MSCs in periodontal surgical animal models, which showed newly formed periodontal tissues, except alveolar bone $[34,35]$. AD-MSCs mixed with platelet rich plasma have been demonstrated to promote regeneration of periodontal ligament-like structures along with alveolar bone in rats [36].

Ozasa et al. indicated a positive effect of the use of AD-MSCs in combination with fibrin gel for periodontal regeneration in 1 and 5 study periods in dogs, reinforcing findings with histological, histo-morphometric, and radiological results, which were consistent with the results of the present study [37].

AD-MSCs transplanted in periodontal defects were shown to favor cementum and periodontum ligament fibers regeneration $[38,39]$. Recent studies also revealed the efficacy of AD-MSCs in repairing bone defects and constructing engineered bone [40-42].

Pourebrahim et al. reported that collagen synthesis in AD-MSCs group of samples was significantly higher than autogenous bone graft at $15^{\text {th }}$ and $60^{\text {th }}$ day in maxillary alveolar cleft model in dogs, while a bone formation was significantly higher in a group, where autogenous bone graft was used [43]. In this study, the composite on the base of bone collagen, hydroxyapatite, and $\mathrm{AD}$ MSCs revealed higher bone formation than the composite on the base of bone collagen and hydroxyapatite [43].

Therefore, clinical applications of AD-MSCs broadly range, and the potential of AD-MSCs demonstrates significant opportunities in tissue engineering.

\section{CONCLUSIONS}

According to the results of our X-ray and morphological examinations, the use of a composite on the base of bone collagen, hydroxyapatite (Col-HA), and AD-MSCs had significantly positive effects contributing to the improvement of reparative regeneration of bone tissue in the area of periodontal bone defect. Therefore, our composite could be useful in future clinical cell-based therapy for periodontal tissue disease in humans after conducting subsequent studies.

\section{ACKNOWLEDGEMENTS}

We would like to thank our consultant Professor Akhmetov B., for his brilliant assistance and enormous help. One of the listed authors has no commercial relationships to declare.

\section{FUNDING SOURCE}

The Ministry of Education and Science of the Republic of Kazakhstan supported this work. The Ministry's involvement was of financial nature only.

\section{References}

1. Liu J, Ruan J, Weir MD, et al. Periodontal bone-ligament-cementum regeneration via scaffolds and stem cells. Cells 2019; 8: 537.

2. Iwata T, Washio K, Yoshida T, et al. Cell sheet engineering and its application for periodontal regeneration. J Tissue Eng Regen Med 2015; 9: 343-356.

3. Gimble JM, Katz AJ, Bunnell BA. Adipose-derived stem cells for regenerative medicine. Circ Res 2007; 100: 1249-1260.

4. Jurgens WJ, Oedayrajsingh-Varma MJ, Helder MN, et al. Effect of tissue-harvesting site on yield of stem cells derived from adipose tissue: implications for cell-based therapies. Cell Tissue Res 2008; 332: 415-426.

5. Lee RH, Kim B, Choi I, et al. Characterization and expression analysis of mesenchymal stem cells from human bone marrow and adipose tissue. Cell Physiol Biochem 2004; 14: 311-324.

6. Citterio F, Gualini G, Fierravanti L, Aimetti M. Stem cells and periodontal regeneration: present and future. Plast Aesthet Res 2020; 7: 41

7. Jones AA, Buser D, Schenk R, Wozney J, Cochran DL. The effect of rhBMP-2 around endosseous implants with and without membranes in the canine model. J Periodontol 2006; 77: 1184-1193. 
8. Rasmussen TP. Embryonic stem cell differentiation: a chromatin perspective. Reprod Biol Endocrinol 2003; 1: 100.

9. Bacakova L, Zarubova J, Travnickova M, et al. Stem cells: their source, potency and use in regenerative therapies with focus on adiposederived stem cells - a review. Biotechnol Adv 2018; 36: 1111-1126.

10. Grayson WL, Bunnell BA, Martin E, Frazier T, Hung BP, Gimble JM. Stromal cells and stem cells in clinical bone regeneration. Nat Rev Endocrinol 2015; 11: 140-150.

11. Trounson A, McDonald C. Stem cell therapies in clinical trials: progress and challenges. Cell Stem Cell 2015; 17: 11-22.

12. Grottkau BE, Lin Y. Osteogenesis of adipose-derived stem cells Bone Res 2013; 1: 133-145.

13. Tsumanuma Y, Iwata T, Kinoshita A, et al. Allogeneic transplantation of periodontal ligament-derived multipotent mesenchymal stromal cell sheets in canine critical-size supra-alveolar periodontal defect model. Biores Open Access 2016; 5: 22-36.

14. Fu X, Jin L, Ma P, Fan Z, Wang S. Allogeneic stem cells from deciduous teeth in treatment for periodontitis in miniature swine. J Periodontol 2014; 85: 845-851.

15. Hasegawa N, Kawaguchi H, Hirachi A, et al. Behavior of transplanted bone marrow-derived mesenchymal stem cells in periodontal defects. J Periodontol 2006; 77: 1003-1007.

16. Cai X, Yang F, Yan X, et al. Influence of bone marrow-derived mesenchymal stem cells pre-implantation differentiation approach on periodontal regeneration in vivo. J Clin Periodontol 2015; 42: 380-389.

17. Monti M, Graziano A, Rizzo S, et al. In vitro and in vivo differentiation of progenitor stem cells obtained after mechanical digestion of human dental pulp. J Cell Physiol 2017; 232: 548-555.

18. Hernández-Monjaraz B, Santiago-Osorio E, Ledesma-Martínez E, Alcauter-Zavala A, Mendoza-Núñez VM. Retrieval of a periodontally compromised tooth by allogeneic grafting of mesenchymal stem cells from dental pulp: A case report. J Int Med Res 2018; 46: 2983-2993.

19. Ferrarotti F, Romano F, Gamba MN, et al. Human intrabony defect regeneration with micrografts containing dental pulp stem cells: a randomized controlled clinical trial. J Clin Periodontol 2018; 45: 841-850.

20. Hughes FJ. Mesenchymal stem cells and periodontal regeneration. Curr Oral Health Rep 2014; 1: 1-8. DOI: doi.org/10.1007/s40496013-0010-7.

21. Pei M, Li J, McConda DB, Wen S, Clovis NB, Danley SS. A comparison of tissue engineering based repair of calvarial defects using adipose stem cells from normal and osteoporotic rats. Bone 2015; 78: 1-10.

22. Zheng CX, Sui BD, Liu N, et al. Adipose mesenchymal stem cells from osteoporotic donors preserve functionality and modulate systemic inflammatory microenvironment in osteoporotic cytotherapy. Sci Rep 2018; 8: 5215

23. Venkataiah VS, Handa K, Njuguna MM, et al. Periodontal regeneration by allogeneic transplantation of adipose tissue derived multi-lineage progenitor stem cells in vivo. Sci Rep 2019; 9: 921.

24. Sawada K, Takedachi M, Yamamoto S, et al. Trophic factors from adipose tissue-derived multi-lineage progenitor cells promote cytodifferentiation of periodontal ligament cells. Biochem Biophys Res Commun 2015; 464: 299-305.

25. Otsu N. A threshold selection method from gray-level histograms. IEEE Trans Syst Man Cybern 1979; 9: 62-66.

26. Brook I. Microbiology and management of periodontal infections. Gen Dent 2003; 51: 424-428.

27. Anitua E, Troya M, Zalduendo M. Progress in the use of dental pulp stem cells in regenerative medicine. Cytotherapy 2018; 20: 479-498.

28. Janko M, Sahm J, Schaible A, et al. Comparison of three different types of scaffolds preseeded with human bone marrow mononuclear cells on the bone healing in a femoral critical size defect model of the athymic rat. J Tissue Eng Regen Med 2018; 12: 653-666.

29. Minichetti JC, D'Amore JC, Hong AY, Cleveland DB. Human histologic analysis of mineralized bone allograft (Puros) placement before implant surgery. J Oral Implantol 2004; 30: 74-82.
30. Wang H, Li Y, Zuo Y, Li J, Ma S, Cheng L. Biocompatibility and osteogenesis of biomimetic nano-hydroxyapatite/polyamide composite scaffolds for bone tissue engineering. Biomaterials 2007; 28: 3338-3348.

31. Zhang W, Abukawa H, Troulis MJ, Kaban LB, Vacanti JP, Yelick PC. Tissue engineered hybrid tooth-bone constructs. Methods 2009; 47: 122-128.

32. Xu XY, Li X, Wang J, He XT, Sun HH, Chen FM. Concise review: periodontal tissue regeneration using stem cells: strategies and translational considerations. Stem Cells Transl Med 2019; 8: 392-403.

33. Portron S, Soueidan A, Marsden AC, et al. Periodontal regenerative medicine using mesenchymal stem cells and biomaterials: a systematic review of pre-clinical studies. Dent Mater J 2019; 38: 867-883.

34. Sabry D, Mohamed E, Elmenofy H, El Ghaffar KA. Evaluation of regenerative potential of adipose: derived stem cells and autogenous bone graft in treatment of periodontal defects. Ain Shams Journal of Dental Science 2014; 17: 29-35.

35. Bassir SH, Wisitrasameewong W, Raanan J, et al. Potential for stem cell-based periodontal therapy. J Cell Physiol 2016; 231: 50-61.

36. Tobita M, Mizuno H. Adipose-derived stem cells for periodontal tissue regeneration. Methods Mol Biol 2011; 702: 461-470.

37. Ozasa M, Sawada K, Iwayama T, et al. Periodontal tissue regeneration by transplantation of adipose tissue-derived multi-lineage progenitor cells. Inflamm Regen 2014; 34: 109-116.

38. Lemaitre M, Monsarrat P, Blasco-Baque V, et al. Periodontal tissue regeneration using syngeneic adipose-derived stromal cells in a mouse model. Stem Cells Transl Med 2017; 6: 656-665.

39. Tobita M, Uysal AC, Ogawa R, Hyakusoku H, Mizuno H. Periodontal tissue regeneration with adipose-derived stem cells. Tissue Eng Part A 2008; 14: 945-953.

40. Lee K, Kim H, Kim JM, et al. Systemic transplantation of human adipose-derived stem cells stimulates bone repair by promoting osteoblast and osteoclast function. J Cell Mol Med 2011; 15: 20822094.

41. Zheng CX, Sui BD, Liu N, et al. Adipose mesenchymal stem cells from osteoporotic donors preserve functionality and modulate systemic inflammatory microenvironment in osteoporotic cytotherapy. Sci Rep 2018; 8: 5215.

42. Pei M, Li J, McConda DB, Wen S, Clovis NB, Danley SS. A comparison of tissue engineering based repair of calvarial defects using adipose stem cells from normal and osteoporotic rats. Bone 2015; 78: 1-10.

43. Pourebrahim N, Hashemibeni B, Shahnaseri S, et al. A comparison of tissue-engineered bone from adipose-derived stem cell with autogenous bone repair in maxillary alveolar cleft model in dogs. Int J Oral Maxillofac Surg 2013; 42: 562-568. 